\title{
Os Sistemas de Atividade na Interpretação da Produção Curricular por 'Situação de Estudo': Fundamentos Teórico-Metodológicos
}

\author{
The Systems of Activity in the Interpretation of Curriculum \\ Production by 'Study Situation': Theoretical-Methodological
}

Fundamentals

\author{
Jaqueline Ritter, Belmayr K. Nery, Otavio A. Maldaner, Andréa B. Umpierre e Tatiane B. Sousa
}

\begin{abstract}
Resumo: O presente texto trata de fundamentos teórico-metodológicos na interpretação dos Sistemas de Atividades para pesquisa em processo de produção curricular inovador desenvolvido em grupo de professores de escola, pesquisadores educacionais, docentes universitários e estudantes em formação universitária, quando aqueles produzem Situações de Estudo (SE) que são acompanhadas na forma de pesquisa em Núcleos de Pesquisa na Escola. O Grupo de Educação Química na Produção Curricular (GEQPC), responsável pela organização e desenvolvimento desse processo, adota o princípio das "tríades de interação profissional". Compreende-se atividade como processo de constituição em Leontiev. Adotam-se princípios da teoria histórico cultural e como processo teórico-metodológico de análise as Teorias da Atividade e dos Sistemas de Atividades. Os primeiros resultados produzidos dão indícios animadores de que a formação continuada de professores no desenvolvimento de SE, em grupo de pesquisa e em núcleo de pesquisa na escola (NPE) tem mais chances de se consolidar quando se explicitam intenções acerca dessas duas "Atividades", quais sejam, a produção curricular e seu acompanhamento pela pesquisa.
\end{abstract}

Palavras-chave: Teoria da Atividade. Teoria dos Sistemas de Atividade. Formação de Professores. Situação de Estudo. Inovação Curricular.

\begin{abstract}
The present text deals with theoretical and methodological foundations in the interpretation of Activity Systems for research in an innovative curricular production process developed in a group of schoolteachers, educational researchers, university professors and students in university formation, when they produce Study Situations (SS) that are tracked in the form of research in Nucleus of Research in School. The Group of Chemical Education in Curriculum Production, responsible for the organization and development of this process, adopts the principle of "professional interaction triads". Activity is understood as a process of constitution in Leontiev. Principles of cultural historical theory are adopted. Theories of Activity and of Systems of Activities are adopted for the theoretical-methodological process of analysis. The first results produced are encouraging signs that the continued formation of teachers in the development of SS, in research group and in research nucleus in school is more likely to consolidate when intentions are made explicit about these two "Activities", that is, the curricular production and its assessment by research.
\end{abstract}

Keywords: Activity Theory. Activity Systems Theory. Teacher Training. Study Situation. Curricular Innovation.

Jaqueline Ritter (jaqueline.ritter@furg.br) possui Doutorado em Educação nas Ciências pela UNIJUí com sanduíche na Universidade Autônoma de Madri, Espanha. Professora-pesquisadora (adjunto) na Escola de Química e Alimentos (EQA) e do Programa de Pós-Graduação em Educação em Ciências: Química da vida e saúde (PPGEC) da Universidade Federal do Rio Grande (FURG). Coordena o grupo de pesquisa GEQPC-FURG. Rio Grande, RS - BR. Belmayr Knopki Nery (belma.nery@ gmail.com) possui Doutorado em Educação pela Faculdade de Educação da Universidade de São Paulo (FE-USP). Integra o Laboratório de Pesquisa em Ensino de Química e Tecnologias Educativas (LAPEQ) como pesquisadora, na área de tecnologias de informação e comunicação, especificamente associadas à formação de professores de Química/Ciências. São Paulo, SP - BR. Otavio Aloisio Maldaner (maldaner@unijui.edu.br) possui Doutorado em Educação pela Universidade Estadual de Campinas. Atualmente é do quadro sênior da UNIJUÍ e professor colaborador da Pós-Graduação em Educação nas Ciências da mesma Universidade. Bolsista de pesquisador visitante do CNPq na FURG. Rio Grande, RS - BR. Andréa Borges Umpierre (andreaumpierre@yahoo.com. br) é licenciada em Física pela (FURG) e mestre em Ensino de Ciências pelo Instituto Federal do Rio de Janeiro (2015). Atualmente é doutoranda do PPGEC/ FURG, bolsista CAPES e integrante do grupo de pesquisa GEQPC/FURG. Rio Grande, RS - BR. Tatiane Beatris Sousa (tatitrisb1@ gmail.com) é graduada em Ciências - habilitação em Química e Especialista em Formação de Professores na Narrativa da Docência (FURG). Atualmente é professora das redes municipal e estadual de ensino e mestranda do PPGEC/FURG e integrante do Grupo de Pesquisa GEQPC/FURG. Rio Grande, RS - BR.

Recebido em 09/09/2018, aceito em 24/11/2018

A seção "Cadernos de Pesquisa" é um espaço dedicado exclusivamente para artigos inéditos (empíricos, de revisão ou teóricos) que apresentem profundidade teórico-metodológica, gerem conhecimentos novos para a área e contribuições para o avanço da pesquisa em Ensino de Química. 
Os grupos de pesquisa (GP) em Educação Química (EQ) sediados nas universidades brasileiras vêm se multiplicando nos últimos anos, em que pese o estabelecimento desses grupos coincidir com o desenrolar da própria história da EQ em nosso país.

Grupos como o GEPEQ da USP, o Grupo de Linguagem e Cognição em Salas de Aula de Ciências da UFMG, o GIPEC da UNIJUÍ, os mais antigos, e os mais novos como o LAPEQ da Faculdade de Educação da USP, LPEQ da UnB, o GPIEQ da UNESP, GPEQsc da USP, campus de São Carlos, EDUQUIM da UFPR, entre outros, colaboram decisivamente para a constituição da nossa Educação Química, no sentido de incrementar a pesquisa na área, como um todo, aprofundar e diversificar as linhas de pesquisa, formar novos pesquisadores, produzir investigações em conjunto com a escola de educação básica, visando aperfeiçoar a prática dos professores e envolvê-los em ações coletivas de ensino, pesquisa e extensão.

Ao mesmo tempo, são recorrentes na literatura manifestações de que os resultados das pesquisas trazem pouca melhoria para o processo de ensino e aprendizagem em Química. Ou seja, a pesquisa, principalmente aquela centrada na pesquisa universitária, não chega à maioria dos professores que, de fato, fazem acontecer o ensino nas escolas básicas, a ponto de modificar a realidade ali existente.

Schnetzler (2002) afirma que

[...] potenciais contribuições da pesquisa educacional não chegam às salas de aula de forma significativa porque, usualmente, os professores, em seus processos de formação inicial (cursos de licenciatura) e continuada não têm sido introduzidos à pesquisa educacional. Por isso, tendem a ignorála, descompromissando-se de investigar a própria prática pedagógica para melhorá-la (p. 22).

Acredita-se que uma das maneiras de fazer chegar as contribuições das referidas pesquisas à sala de aula da escola básica é aproximar os dois locus de atuação profissional, bem como os pesquisadores e os professores que neles atuam. Para que os docentes em formação sejam introduzidos na pesquisa, como defende Schnetzler, espaços precisam ser criados, com intencionalidade formativa dirigida à prática da pesquisa. Uma possibilidade de realização da aproximação universidade e escola, e de criação desses espaços, são as "tríades de interação profissional" (Zanon, 2003), constituídas pelo professor universitário, professor do ensino médio e licenciandos. De acordo com Schnetzler (2002, p. 22) as tríades implicam

[...] no tratamento de um determinado conteúdo químico (ou pedagógico) da disciplina não somente pelo professor universitário, mas, também, por parte do professor do ensino médio, incentivando a discussão de reelaborações conceituais ou transposições didáticas mais adequadas à futura docência dos licenciandos. Consequentemente, são enfatizadas articulações entre saberes disciplinares e saberes inerentes à docência escolar, contribuindo para minimizar a cisão teoria-prática em cursos de formação de professores de química (Schnetzler, 2002, p. 22).

Os grupos de pesquisa desempenham papel central na criação e desenvolvimento das referidas tríades, pois eles congregam pesquisadores, professores experientes, pesquisadores iniciantes e futuros professores (licenciandos), cada qual com suas necessidades formativas e seus percursos profissionais, de tal forma que as interações constitutivas entre os sujeitos são ricas e diversificadas. Os licenciandos, de fato, são os sujeitos que fazem o contato direto com a escola e nela com os professores que atuam nas salas de aula, ao cursarem as disciplinas relativas ao estágio profissional e aquelas voltadas à prática como componente curricular conforme preveem as atuais Diretrizes para a Formação de Professores (Brasil, 2015). No entanto, ainda é frágil o envolvimento direto do professor da escola com os professores universitários, de modo que investir nas "tríades de interação profissional" mostra-se um caminho promissor de aproximação universidade e escola, minimizando as dicotomias formação e trabalho, ensino e pesquisa.

Nesse sentido, o Grupo de Educação Química na Produção Curricular em Ciências da Natureza, (GEQPC), que tem sede na Universidade Federal do Rio Grande (FURG), é um grupo de pesquisa que vem trabalhando na perspectiva das "tríades". Criado em 2015, o GEQPC, congrega sujeitos de diversificados contextos de formação e atuação/trabalho na intenção de ressignificar os conhecimentos científicos e pedagógicos específicos da área de Ciências da Natureza pela sua recontextualização em processos de ensino e seu acompanhamento pela pesquisa, na interface universidade e escola.

O objetivo do grupo é subsidiar teórica e metodologicamente a implementação de pequenos núcleos de pesquisa nas escolas de educação básica (NPE), em cada área de conhecimento, cujo objeto de estudo e de pesquisa é a própria prática curricular que o professor desenvolve (Ritter, 2017), na perspectiva de promover a formação dos sujeitos envolvidos, por meio da prática de reorganização curricular, tendo como dispositivo formativo a atividade de produção de Situações de Estudo (SE) (Maldaner, 2007).

Os pressupostos da reorganização curricular, baseada em Situação de Estudo (SE) (Maldaner, 2007), como o principal dispositivo de formação, seguem a trajetória do Grupo Interdepartamental de Pesquisa sobre Educação em Ciências (GIPEC - UNIJUÍ). Segundo esses pressupostos, por meio de sucessivas SE pode ser definida uma nova compreensão de currículo que contribui para a construção de significados dentro do contexto escolar (Gehlen et al., 2005; Auth et al., 2004), de modo a enfrentar a fragmentação disciplinar e, principalmente, levar a significação conceitual da linguagem científico-escolar, em cada área do conhecimento. Baseado nisso, o GEQPC iniciou no ano de 2016, com uma escola de educação básica parceira, um processo de instituição de núcleos de pesquisa 
na escola por área de conhecimento, cujo objeto de pesquisa e formação é a produção curricular por SE.

De acordo com a Teoria dos Sistemas de Atividade (TSA) (Engeström et al., 1999), um grupo de pesquisa é um complexo sistema de atividades executadas por muitos sujeitos. Esse sistema é formado por diversos subsistemas que interagem entre si com o propósito de realizar pesquisa. Porém, o grupo de pesquisa também se constitui em um subsistema de um sistema de atividades maior, como, por exemplo, o sistema das atividades universitárias em geral. Sendo assim, uma teoria que interpreta sistemas organizados, em funcionamento, nos parece apropriada para pesquisar e explicitar as "atividades" desenvolvidas em processos interativos envolvendo o GEQPC e a escola de educação básica, em seus desafios e potencialidades.

A Teoria dos Sistemas de Atividade, desenvolvida por Yrjö Engeström et al. (1999) e a Teoria da Atividade (TA) idealizada por Leontiev $(1978 ; 1988)$ fundamentam teórica e metodologicamente as análises neste artigo.

Assim, com apoio da TA e da TSA, o objetivo deste trabalho consistiu em identificar os principais Sistemas de Atividade (SA) que constituem o GEQPC na interface com uma escola de educação básica parceira, visando analisar o mais representativo deles no sentido do desenvolvimento da Atividade de produção curricular por meio da elaboração de uma Situação de Estudo, quando mediada pela constituição de um NPE, o qual institui gradativamente a pesquisa docente como atividade formativa/constitutiva dos sujeitos. Em resumo, perguntou-se: quais processos de desenvolvimento/formação (motivo, ação e operação) estão constituindo e mediando as interações entre o grupo de pesquisa GEQPC e a escola de educação básica, na produção curricular por SE?

\section{Alguns Fundamentos das Teorias da Atividade e dos Sistemas de Atividade}

A Teoria da Atividade evoluiu ao longo de três gerações de pesquisa, segundo Engeström et al. (1999). A primeira geração, centrada em Vigotski, criou a ideia de mediação. Esta ideia tomou forma no famoso modelo triangular de Vigotski (2001), no qual a conexão direta condicionada entre estímulo e resposta foi superada, transcendida pela ideia de que a atividade é um ato complexo, mediado, e é representada pelo trio - sujeito, objeto e artefato mediador - colocados nos vértices de um triângulo.

Leontiev, derivando os estudos de Vigotski, cunhou a expressão Teoria da Atividade e sugeriu o modelo triangular desta primeira fase da Teoria. Conforme a TA, o sujeito exerce uma atividade, ou seja, atinge o objeto da sua atividade, por meio de artefatos mediacionais. Contudo, nota-se que nesta primeira fase não havia espaço para as relações sociais e para o outro. A limitação desta primeira geração da teoria reside justamente no fato de que a unidade de análise permanece focada no indivíduo. Isso foi superado pela segunda geração da TA, baseada no trabalho de Leontiev. E é no seu famoso exemplo da "caça primitiva coletiva" (Daniels, 2003) que ele explica a diferença crucial entre uma ação individual e uma atividade coletiva.

Leontiev não representou graficamente a atividade coletiva, acredita-se, muito pelo contexto político da época no seu país. Porém, ele elaborou o chamado "modelo dos três níveis" (Leontiev, 1988), em que faz a distinção entre atividade, ação e operação. O teórico considera que os seres humanos se constituem e se desenvolvem por meio das atividades, as quais são dirigidas a objetos a serem alcançados e são orientadas por ações intencionais. Enquanto uma atividade é orientada por um motivo, as ações são orientadas por metas e as operações por condições.

O triângulo a seguir (Figura 1), que configura a atividade coletiva, foi criado por Engeström, traduz a estrutura de um sistema de atividade humano e também simboliza a segunda geração da TA.

O sujeito atinge o objeto da sua atividade por meio dos artefatos mediacionais, mas este sujeito também pertence a uma comunidade, está subordinado a regras e tem um papel na divisão do trabalho. Esta é a conformação da segunda fase

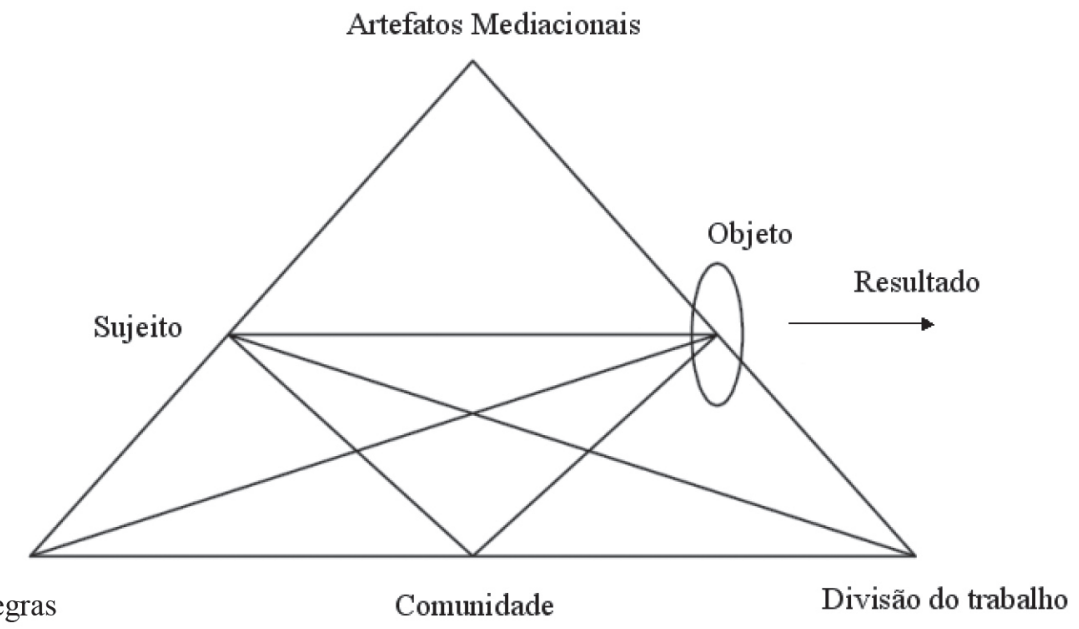

Figura 1: Esquema dos elementos de um Sistema de Atividade. Fonte: a partir de Daniels (2003). 
da TA, com lugar para o outro, representando os outros no elemento COMUNIDADE do esquema.

Segundo Engeström et al. (1999) o subtriângulo superior deve ser visto como a ponta de um iceberg, simbolizando as ações individuais aninhadas, ocultas, neste sistema de atividades coletivas. $\mathrm{O}$ objeto é mostrado com a ajuda de uma figura oval, indicando movimento e que as ações orientadas para o objeto são sempre, explícita ou implicitamente caracterizadas por ambiguidade, surpresa, interpretação, busca de sentido e têm potencial para mudanças.

De acordo com os pressupostos teóricos da Teoria da Atividade, o sujeito aprende em atividade, que é mediada por artefatos. O sujeito cria os artefatos e, ao colocá-los em uso, os desenvolve; mas, ao mesmo tempo, se desenvolve ao fazê-lo.

A Teoria dos Sistemas de Atividade postula mais três elementos que influenciam a atividade do sujeito: a comunidade em que ele está inserido, a divisão do trabalho nessa comunidade e as regras a que ele está submetido nessa mesma comunidade, como ilustrado na Figura 1.

Ainda de acordo com essas duas teorias, o sujeito em atividade - no caso do GEQPC, a atividade é predominantemente intelectual - desenvolve as funções psicológicas superiores. À vista dos pressupostos da TSA, em que existem mais três componentes que influenciam diretamente a atividade do sujeito, esta não pode ser estudada isoladamente. Ela pode ser definitivamente entendida somente quando interpretada tendo como pano de fundo todos os SA constituintes do grupo de pesquisa.

Daniels (2003) apresenta um resumo da TSA, sugerido por Engeström, com a ajuda de cinco princípios, os quais manifestam o estado da teoria atualmente e que são minuciosamente expostos na sua obra (p. 123-125). O primeiro princípio preceitua que a unidade primária de análise "é um sistema de atividade coletivo, mediado por artefato e orientado para o objeto, visto em suas relações de rede com outros sistemas." O segundo é o princípio da multivocalidade, ou seja, um sistema de atividade é sempre uma comunidade de múltiplos pontos de vista, tradições e interesses. A historicidade é o terceiro princípio. O quarto princípio é representado pelo papel central das contradições como fontes de mudança e desenvolvimento. E o quinto princípio "proclama a possibilidade de transformações expansivas nos sistemas de atividade."

Importa mencionar que as duas Teorias respondem a diferentes problemas de pesquisa, na área da educação e em outras áreas também. Há grupos de pesquisa em TA e TSA consolidados, a exemplo do GEPAPe, Grupo de Estudos e Pesquisa sobre a Atividade Pedagógica, sediado na Faculdade de Educação da Universidade de São Paulo (FEUSP), que busca compreender os processos de transformação dos sujeitos em atividade, sejam eles estudantes, professores ou gestores participantes de comunidades educativas, em processos relacionados à educação matemática. No que se refere à educação química, o LAPEQ, Laboratório de Pesquisa em Ensino de Química e Tecnologias Educativas, também sediado na FEUSP, ainda que com menos tradição de pesquisa em TA e TSA, vem pesquisando diferentes objetos à luz das duas teorias, a exemplo dos trabalhos de Nery e Giordan (2013), Nery (2014), Massi e Giordan (2017) e Lima e Giordan (2018).

No âmbito internacional, tem-se o grupo CRADLE, ${ }^{1}$ Center for Research on Activity, Development and Learning, na Universidade de Helsinki, que focaliza estudos de transformações em sistemas de atividade coletivos, incluindo instituições educacionais, organizações profissionais, agências do setor público, comunidades e movimentos sociais e suas alianças. Importa lembrar igualmente que há a ISCAR, ${ }^{2}$ International Society for Cultural-Historical Activity Research que congrega pesquisadores em TA e TSA no mundo todo. Há também a ISCAR Brasil, ${ }^{3}$ a seção brasileira da Sociedade. A ISCAR publica anualmente uma revista, Mind, Culture and Activity: an International Journal, que atesta a diversidade de temas pesquisados com fundamento teórico na TA e TSA. Pode-se encontrar desde temas derivados dos tradicionais, pesquisados pelos precursores da escola russa, até estudos de identidade discursiva em "tribos" de jogadores de videogame on-line, travestidos em avatares, publicado já em 2006. Essa diversidade de problemas pesquisados é uma das razões pelas quais as teorias são tão consistentes.

\section{O GEQPC e as "Tríades de Interação" na Constituição dos NPE}

O Grupo de Educação Química na Produção Curricular, da FURG, é constituído e vem se desenvolvendo na perspectiva das "tríades de interação profissional" (Zanon, 2003). Com o intuito de promover a formação continuada e permanente como desenvolvimento profissional entre todos os seus sujeitos, o GEQPC propôs-se a mediar diálogos em torno da produção curricular por SE acompanhada pela pesquisa. Parte-se do pressuposto de que se trata de duas práticas que concebem a docência: a produção curricular e a pesquisa que, quando explicitada, discutida e teorizada, pode conduzir à constituição das habilidades de professor-pesquisador de práticas docentes escolares e universitárias e habilidades para qualificar processos de intervenção pedagógica nesses dois contextos. Habilidades são aqui entendidas como tudo aquilo que é capaz de significar e mobilizar os diferentes domínios de conhecimentos e atitudes (Ritter, 2017) e que, como tal, argumenta-se carecerem de ser desenvolvidas em processos interativos/formativos. Dá-se ênfase à significação da linguagem científico-escolar na relação com temas de natureza interdisciplinar e intercomplementar inovadores, no sentido de resultar em aprendizagens mais efetivas e duradouras.

Defende-se que a constituição de pequenos grupos de pesquisa na escola, NPE, que se realizam na interface com a universidade, é um meio capaz de criar a necessidade de o professor tornar-se pesquisador de sua prática curricular e poder aperfeiçoá-la mediante ações didáticas inovadoras. Contudo, 
esta nem sempre é uma necessidade consciente do professor na sua rotina docente, mas pode vir a ser, desde que o meio seja encorajador para tal.

$\mathrm{O}$ ato de pesquisar sobre algo e comunicar seus resultados é competência a ser desenvolvida progressivamente como qualquer aprendizagem. Embora tenha-se a capacidade de aprender como herança genética, é somente por meio de nossa inserção no universo cultural da pesquisa que se aprende a pesquisar como modo de produzir conhecimentos sobre os fenômenos, ou qualquer objeto referente. Ninguém nasce sabendo fazer pesquisa! Aprende-se a pesquisar, assim como se aprende um novo idioma, e é por meio de sua apropriação, como ferramenta técnica e psicológica, que se atinge níveis mais elevados de consciência e desenvolvimento, segundo Ritter (2017), com base em Vigotski (2001). No caso, a pesquisa capaz de instituir competências e habilidades é aquela que se refere tanto à produção coletiva da Situação de Estudo nos NPE, quanto àquela realizada pelo professor no exercício de avaliar o seu desenvolvimento pelo aprendizado dos alunos.

Indagar, levantar hipóteses, produzir dados, analisá-los à luz de referenciais teóricos e encontrar meios válidos para comunicá-los e validá-los produz níveis mais avançados de generalização mental e procedimental. Portanto, são habilidades que, articuladas a conhecimentos e atitudes, promovem novos níveis de consciência sobre si e sobre o mundo. São, portanto, competências específicas do ser humano que, por sua vez, são instituídas e desenvolvidas nas relações sociais e culturais das quais participa. Para os estudantes o caminho para tal desenvolvimento é a significação e apropriação de conceitos científicos escolares, cujo acesso compete à escola proporcionar. Para os professores, a formação coletiva em grupos de pesquisa, na área de conhecimento, permite qualificar tanto o professor em atividade investigativa quanto o seu próprio objeto: o currículo em desenvolvimento.

Assim, pesquisar o objeto referente SE em processos colaborativos e mediados pelo GEQPC e os NPE, tornar-se-á "Atividade" na medida em que as ferramentas mediacionais instituírem sempre novos e mais avançados estados de abstração e generalização, os quais geram novos níveis de competências e habilidades. A pesquisa como exercício mental e procedimental de ler, escrever, interpretar, selecionar, argumentar, torna-se manifestação do desenvolvimento do pensamento abstrato e categorial, sendo, portanto, competência significada e apropriada, conforme Ritter (2017), com apoio teórico de Vigotski (2001).

Para o teórico russo (Vigotski, 2007), o conceito de mediação envolve o uso de instrumentos e de signos, constituindo o cerne do comportamento humano complexo. Segundo Vigotski, "Os sistemas de signos (a linguagem, a escrita, o sistema de números), assim como o sistema de instrumentos, são criados pelas sociedades ao longo do curso da história humana e mudam a forma social e o nível de seu desenvolvimento cultural" (p. 26). Ele afirma que a internalização dos sistemas de signos produzidos culturalmente provoca transformações comportamentais e estabelece um elo de ligação entre as formas iniciais e tardias do desenvolvimento individual (Vigotski, 2007).

Vigotski (2007) caracteriza como "internalização" a transformação de uma operação externa em interna. Este conceito permite o reconhecimento da importância dos processos interativos "triádicos" que são internalizados em saberes e práticas docentes na intermediação do GEQPC e o NPE. Novos níveis de desenvolvimento podem vir a ser evidenciados quando os motivos, as condições e operações da atividade de produção da SE e acompanhamento pela pesquisa forem explicitados, significados e internalizados. Este é, fundamentalmente, o propósito pretendido pelo GEQPC.

\section{A Situação de Estudo na Produção Curricular no Âmbito da Escola}

Ao propor a elaboração conjunto de Situações de Estudo, parte-se do pressuposto de que "a elaboração de um novo modelo pedagógico só terá êxito se for instaurado na forma de produção coletiva de professores e estudiosos de currículos e propostas escolares em Ciências e nos demais componentes [curriculares]". (Araújo et al., 2013, p. 243). O GEQPC, conforme descrito anteriormente, tem como característica a produção interativa de um novo modelo de atividade curricular nas escolas, que é a organização dos conteúdos escolares em sucessivas SE. Igualmente, dentro dos pressupostos teóricos da Teoria Histórico Cultural (THC), os processos interativos que acontecem na produção das SE, sua implementação em sala de aula e acompanhamento pela pesquisa, são constitutivos e formativos de todas as pessoas envolvidas.

Maldaner e Zanon (2001), ao discutirem a organização curricular com base em SE, reafirmam as pretensões formativas nesses processos com base na THC e pela concepção partilhada do próprio sentido atribuído à missão da escola: proporcionar o acesso sistemático e intencional aos conhecimentos históricos pelas novas gerações, promovendo, por esse meio, o desenvolvimento intelectual.

A formação dos alunos e dos professores faz parte de uma construção coletiva de espaços de interação propiciados pela escola e pelo sistema de ensino, com a participação, também, da comunidade escolar. Na produção e no desenvolvimento de uma situação de estudo visa-se, justamente, criar novas interações nos coletivos escolares, pois é nelas que as pessoas aprendem e se desenvolvem (Maldaner e Zanon, 2001, p. 59).

Por definição, a Situação de Estudo ou uma situação a ser estudada no contexto escolar parte da vivência dos estudantes ou do mundo vivido por eles, sobre a qual eles têm a algo a dizer, manifestando entendimentos, e produzindo argumentos com pontos de vista diferentes. Cabe ao professor introduzir conceitos disciplinares que apontem abordagens e entendimentos 
próprios das disciplinas escolares. Por isso mesmo, a situação a ser estudada, em processo interativo de estudantes e professores, deve ser conceitualmente rica no que se refere aos sistemas conceituais de uma ou mais disciplinas escolares, permitindo novos níveis mais abstratos de entendimento por meio da significação conceitual. Dessa forma, os estudantes tomam consciência dos próprios entendimentos anteriores e aprendem novos pontos de vista mais consistentes, historicamente produzidos e muitas vezes testados sobre a situação em estudo. Vigotski (2005) afirma que pontos de vista das Ciências, introduzidos com a ajuda de conceitos científicos, permitem tomada de consciência dos conhecimentos anteriores pela reflexão. "A consciência reflexiva chega à criança através dos portais dos conhecimentos científicos" (Vigotski, 2005, p. 115). Além disso, é favorecida a significação intersubjetiva, que é constitutiva do intelecto, conforme propõe Vigotski. Nesse desdobramento curricular os conceitos fazem sentido no contexto em que se inserem, produzindo aprendizagens dos conteúdos escolares com melhor qualidade. Os conceitos disciplinares mais estruturadores vão aparecer em novas SE, pois elas se sucedem nessa organização curricular, o que leva a avaliar os sentidos anteriores, permitindo sua evolução para níveis superiores de abstração em direção aos significados históricos. Vigotski (2005) entende que o significado histórico de um conceito não acontece com o primeiro contato, mesmo que seja contextualizado e faça algum sentido. Em novas situações e novos processos escolares, o mesmo conceito precisa ser novamente introduzido, dando chances à evolução de sentido em nível mais abstrato.

Há, hoje, um considerável número de trabalhos que propõem e pesquisam sobre a organização curricular em SE, como o trabalho de Vieira et al. (2018). O número de trabalhos produzidos em pouco tempo mostra que diferentes grupos de professores de escola e professores de universidade começam a assumir mais a questão da elaboração curricular sob novo enfoque, quebrando a rigidez de sequência dos conteúdos disciplinares. É esta a forma humana histórica com que novos paradigmas científicos ou abordagens pedagógicas vão tomando corpo, proporcionando avanços teórico-práticos, no caso, em ações pedagógicas curriculares. No mesmo sentido buscamos compreender a SE à luz de princípios da Teoria da Atividade, com base em Leontiev. Esses princípios inserem-se na mesma matriz teórica histórico-cultural de base vigotskiana, mas que explicita novas nuances teóricas que podem ser interessantes para se avançar na compreensão do papel da escola na vida das novas gerações. A partir desse autor, compreende-se que a TA pode explicitar sob outro viés a questão da constituição da consciência na e da prática docente como um trabalho social de grande relevância na criação/recriação cultural pelas crianças e jovens na escola e pelos professores em sua vida profissional. Já se discutiu bastante em pesquisa educacional que o professor em sala de aula acaba criando currículo de uma forma ou de outra, mesmo que siga propostas curriculares de autores de livros didáticos ou de outros materiais pedagógicos de cuja criação não participou. Dessa forma, não há currículo escolar, mesmo que "imposto" por quem quer que seja (redes de ensino, administrações públicas, pesquisadores educacionais, entre outros), à "prova de professor". Quando isso acontece, na maioria das vezes, culpa-se o professor pela pouca aprendizagem dos alunos, pois sempre há o entendimento de que os "especialistas" sejam os mais capacitados para dizer o que é melhor. Estes podem e devem dar diretrizes que atendam a decisões democráticas sobre o que, como e porque ensinar determinados conteúdos e a forma de fazê-lo, mas não podem esperar que essas diretrizes possam ser implementadas na prática do ensino sem a participação intensa e qualificada dos professores.

Produzir currículo na educação escolar, na forma proposta pela organização por meio de sucessivas SE, visa proporcionar espaços e condições de produção e implementação das práticas curriculares, proporcionando autonomia gradativa a professores e estudantes em seus processos interativos no contexto da educação escolar básica, sem deixar de seguir diretrizes republicanas em vigor. Por isso, defende-se que é condição necessária a participação de professores universitários que trabalham com formação de professores nas licenciaturas, estudantes dessas licenciaturas, pesquisadores educacionais, como docentes de pós-graduação e seus pós-graduandos, da forma como propõe o GEQPC, incluindo, em fase posterior, a produção dos estudantes da educação básica.

Ao analisar como isso pode estar acontecendo no campo da prática, optou-se pelos sistemas de atividade, pois se compreende que o processo de produção e organização curricular em SE contempla diversas dimensões na constituição do psiquismo humano, segundo propõe Leontiev (1978) pela TA. Pode-se indicar algumas dessas dimensões: Atividade Humana Histórica; Atividade Principal; Atividade da Escola; Atividade do Ensino; Atividade do Estudo. Essas dimensões dão-se nos indivíduos em diversas situações e etapas de sua vida. Na sociedade contemporânea, letrada e tecnológica, pode-se pensar em etapas da vida, como: pré-escolar; escolar; universitária (preparação profissional); exercício profissional. Em todas elas há o que Leontiev (1978) denomina ATIVIDADE PRINCIPAL.

$\mathrm{Na}$ atividade principal, os sujeitos estão especialmente disponíveis para sua constituição psíquica/intelectual/formação da consciência. Ela, porém, só vai acontecer a partir da necessidade, que não é natural, mas historicamente criada pela humanidade. A necessidade é também de dimensão biológica, a qual nunca é suprimida, mas nos humanos adquire nova dimensão, a cultural, que engloba objetos e outras necessidades de cunho sociocultural. Por isso, o movimento em direção à atividade principal precisa ser igualmente de criar condições para acontecer em cada uma das etapas, como: a vivência cultural e os brinquedos decorrentes; a presença dos livros e outros meios da atividade de crianças e adolescentes na escola; a ênfase na formação profissional técnica ou superior na juventude; 
condições dignas de trabalho, não alienado, isto é, trabalho produtivo e criativo (criador), muito além das necessidades biológicas de comer, vestir, morar e reproduzir.

Da mesma forma que em qualquer outro trabalho, se professores e estudantes estiverem distantes da atividade curricular produtiva e criativa, a atividade principal do ensino e do estudo estará ausente. Haverá, apenas, repetição alienada de conteúdos e tarefas escolares. Isso costuma acontecer quando a preocupação é tão somente desenvolver os itens de conteúdos escolares recomendados em conteúdos mínimos, seja na forma de programas de avaliação, como os vestibulares e o ENEM, seja por algum autor de livro didático, órgão administrativo ou da própria escola. Quando isso acontece, os professores não assumem a responsabilidade do ensino como criação e produção, nem os estudantes assumem seu estudo como atividade constitutiva de seu intelecto e da consciência de ser social participativo e solidário. A simples abordagem de itens desses programas não faz sentido nem para professores e muito menos para estudantes. O motivo das ações fica distante, não acontecendo a atividade constituinte de consciência. Ao buscar entender uma situação que está sendo estudada, os conteúdos e conceitos introduzidos pela prática pedagógica adquirem sentido, e desenvolvem a consciência sobre o real dado. Na SE, por propiciar o movimento do pensamento sobre o real com a introdução de um sistema conceitual histórico (pela disciplina escolar), proporciona-se o que Vigotski (2005) identificou como "o processo da formação de conceitos em toda sua complexidade [...]", o qual "surge como um movimento do pensamento dentro da pirâmide de conceitos, constantemente oscilando entre duas direções, do particular para o geral e do geral para o particular [...]" (p. 100-101).

São esses aspectos que a SE busca superar, conforme segue.

\section{Metodologia da Pesquisa Realizada}

Pensamos, como hipótese, que a forma de produção, implementação e desenvolvimento de SE em sala de aula, e seu acompanhamento pela pesquisa, envolve de forma criadora e produtiva todos os grupos de sujeitos, sendo, portanto, constitutiva da consciência de todos. O mesmo processo, por decorrência da definição de SE e pelos pressupostos teóricos adotados, é constituinte de consciência por contemplar a colaboração entre pares, tornando-se trabalho coletivo e processo de internalização das relações sociais. A análise de indícios dessa consciência pelo estudo dos sistemas de atividade poderá indicar essa possibilidade com o passar do tempo, pois a proposta formativa de todos é de médio e longo prazo. Diferente de buscar esses indícios apenas, por exemplo, nos estudantes, os sistemas de atividade permitem fazê-lo, num mesmo grupo colaborativo em todos os seus sujeitos.

Para que fossem identificados os principais SA constituintes do GEQPC nomeamos os sujeitos que integram o GP. São eles: coordenador, licenciandos, pós-graduandos, professores da escola parceira, professor formador interno e externo ao GP, pesquisador visitante e funcionários de apoio técnico-administrativo-pedagógico.

Representamos por meio do triângulo (Figura 1), que consideramos uma ferramenta de análise, os elementos do SA que tem como sujeito o professor da escola parceira integrante do GEQPC, além do SA designado 'Pesquisa no GEQPC'.

As análises consideraram uma característica do modelo teórico de Engeström que é o fato de os SA interagirem e formarem redes de SA (1999). Este é um princípio fundamental para analisarmos, neste referencial teórico, processos que envolvem esferas distintas de produção humana ou a participação de grupos sociais diversificados, como aqueles deflagrados em GP para fins de realização de pesquisa e formação de professores.

Além de identificar os SA, esta análise consistiu em reconhecer, por meio da enunciação dos sujeitos, elementos que caracterizam a produção e desenvolvimento de uma SE como Atividade, orientada por um motivo, qual seja, a produção curricular, bem como quais ações e operações são evidenciadas neste momento, como da criação dos NPE.

Para isso, o material empírico analisado foi a transcrição da gravação de um encontro realizado no âmbito da escola, que contou com todos os sujeitos do GEQPC e da escola parceira, em momento de teorização sobre os pressupostos orientadores da produção curricular e seu acompanhamento pela pesquisa nos NPE, qual seja, a abordagem histórico-cultural, com base em Vigotski, Leontiev, e seus contemporâneos. Da transcrição desse encontro, foram selecionados episódios, os quais foram analisados à luz da TA e da TSA na sequência. Para análise dos dados, foi usada a metodologia de análise de conteúdo de Bardin (1977), em que o material empírico é organizado em três partes: primeira, a pré-análise, em que é feita uma leitura flutuante e a escolha dos documentos, seguida da exploração do material, e a terceira é o tratamento dos resultados, a inferência e a interpretação.

Todos os episódios analisados passaram pelo critério de categorização, em que foi possível identificar a presença ou não dos conceitos que fundamentam a TA e TSA. As categorias foram obtidas a partir da análise exploratória do material empírico. O tratamento dos dados, por meio de categorias, deu-se na sua conjunção com o referencial teórico da SE, TA e da TSA.

Neste trabalho, exploramos a categoria: APROPRIAÇÃO TEÓRICA DA SE. Assim, os episódios analisados se referem a ela.

\section{Discussão dos Resultados}

$\mathrm{Na}$ interpretação dos sistemas de atividade, conforme a TSA, os sujeitos compartilham objetos em uma comunidade da qual participam. Esses objetos podem ser propósitos ou motivos que mobilizam a comunidade na resolução de problemas, ou seja, na execução da atividade. Além disso, a comunidade compartilha um conjunto de ferramentas culturais, que são os 
meios mediacionais necessários à interação entre os sujeitos, e deles com o mundo material em seu entorno. No caso do SA 'Pesquisa no GEQPC' (Figura 2), que é um SA “maior”, constituído de pelo menos oito SA "menores", os objetos variam. Cada sujeito tem seu objeto particular, mas eles compartilham um objeto comum que, do ponto de vista deste trabalho, é a produção curricular.

Foi possível identificar oito Sistemas de Atividade componentes do SA Pesquisa no GEQPC, cujos sujeitos realizam atividades paralelas em outros SA que, em conjunto, constituem a atividade coletiva do Grupo: Coordenação, Participação pesquisador visitante, Participação professor formador externo, Participação professor formador interno, Participação pósgraduandos, Participação licenciandos, Participação professor da escola parceira e Apoio técnico-administrativo-pedagógico.
Ao identificar os SA constituintes do GEQPC, entende-se que o SA Participação da escola parceira, que tem como sujeito o professor da escola, é o que lhe confere a identidade de grupo de pesquisa na perspectiva das referidas tríades (Zanon, 2003): um sujeito em processo formativo, que tem participação em palestras e reuniões, produção de Situações de Estudo, desenvolvimento da SE produzida em sala de aula, pesquisa sobre este desenvolvimento, que constitui pesquisa sobre a própria produção curricular. Por isso, optou-se por apresentar somente o esquema do SA Participação da Escola Parceira, que tem como sujeito o Professor da escola parceira (PE) (Figura 3).

O sujeito Professor da escola parceira em atividade de produção de uma SE, o faz por meio dos artefatos mediacionais citados no vértice superior do triângulo, entre outros. Está submetido às regras do GP, mas também às regras da escola

Situação de Estudo, Grupo de pesquisa na escola, Recursos físicos, Instrumento de pesquisa, Teorias de currículo

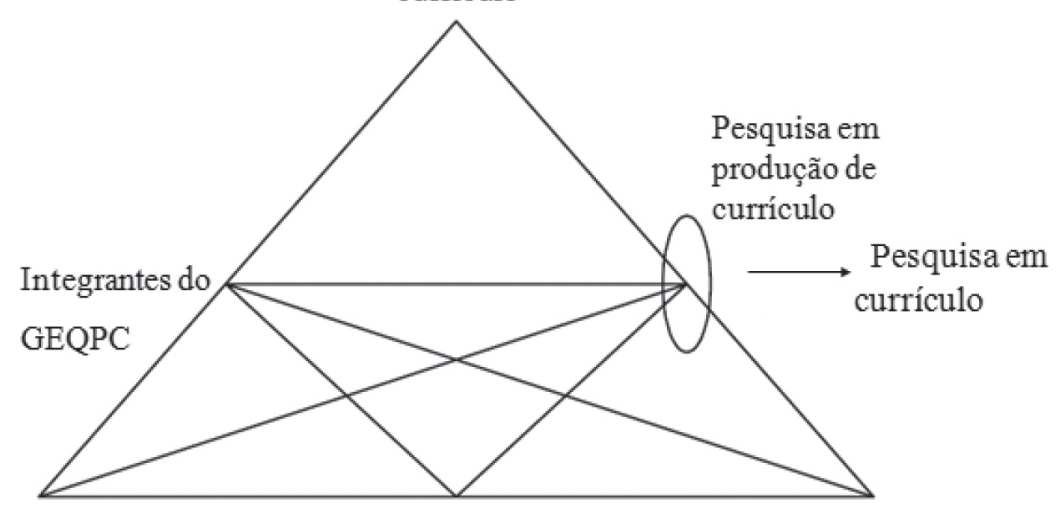

Regras do GEQPC, Regras do CNPq, dos GPemEQ
Pesquisadores em EQ, comunidade de GP
Realização de pesquisa em $E Q$, realização de pesquisa em currículo.

Figura 2: Esquema representativo do SA Pesquisa no GEQPC. Fonte: a partir de Engeström et al. (1999).

Softwares, computador, conceitos científicos, teoria de aprendizagem e desenvolvimento, livros de consulta

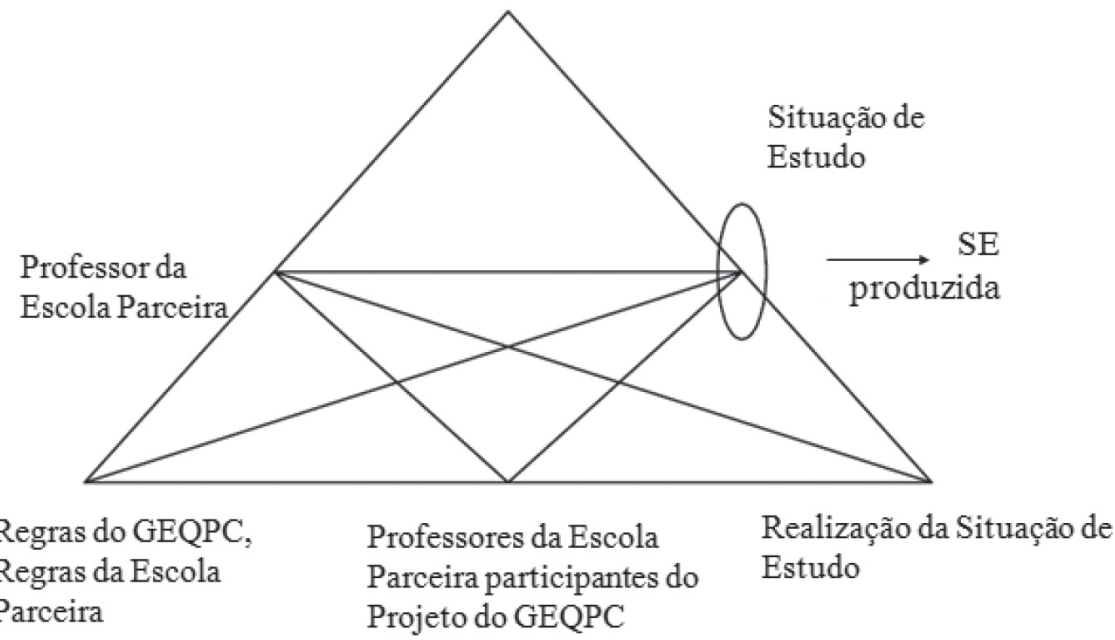

Figura 3: Esquema representativo do SA Participação Professor da Escola Parceira. Fonte: a partir de Engeström et al. (1999). 
parceira, tal como horário de realização das tarefas escolares. Ele pertence à comunidade de professores da escola parceira participantes do GEQPC, que estão engajados no processo de produção de SE e desempenha o papel de realizador da SE. Seu lugar é de sujeito da interface universidade $\mathrm{x}$ escola, por atuar nesses dois contextos (Vasconcelos et al., 2017).

Reconhece-se, nos princípios da TSA citados anteriormente, uma possibilidade teórica, mas também metodológica, de análise para o SA Participação Professor da Escola Parceira, identificado, para efeito deste artigo, como fundamental no quadro constitutivo do GP.

Assim, de acordo com o primeiro princípio, o SA Participação Professor da Escola Parceira não pode ser interpretado isoladamente: deve ser visto em sua rede de relações com outros SA que, ressalte-se, podem não ser necessariamente os outros sete nomeados - Coordenação, Participação pesquisador visitante, Participação professor formador externo, Participação professor formador interno, Participação pós-graduandos, Participação licenciandos e Apoio técnico-administrativopedagógico. De fato, a atividade de produção da SE pelo professor da escola parceira não se realiza sem as demais atividades dos sujeitos dos outros SA. Essas atividades se constituem em meio aos seus motivos, digamos, laterais, para atender prioritariamente às necessidades do professor da escola parceira no intuito de fazê-lo atingir o objeto da sua atividade, qual seja, a produção da SE. Operacionalmente, a relação entre os SA se estabelece, via de regra, por meio das ferramentas culturais veiculadas nas interações do GEQPC com os sujeitos componentes do grupo como um todo. Essas interações, objetivadas, materializam as atividades de cada sistema. Há ainda outros importantes vínculos entre os SA mediante a divisão de trabalho e as regras de funcionamento de cada SA.

A atividade do pesquisador visitante se assemelha, em alguns aspectos, à de um professor na sala de aula, pois protagoniza a exposição dos fundamentos teóricos da SE nas reuniões com o grupo completo, discute, esclarece dúvidas sobre ela, e assessora a coordenação nos assuntos relacionados à pesquisa em GP propriamente, pois tem acumulada extensa experiência profissional nesse campo.

O professor formador externo, sujeito do SA Participação professor formador externo, também atua de forma semelhante a um professor na sala de aula, porque, quando solicitado, expõe, explica, discute, contextualiza os fundamentos das Teorias da Atividade e dos Sistemas de Atividade - ações dirigidas principalmente à parte do grupo que faz pesquisa universitária, os pós-graduandos.

O professor formador interno apresenta os fundamentos teóricos e práticos para a realização de todas as etapas da produção coletiva da Situação de Estudo, bem como do seu desenvolvimento. Introduz signos específicos do campo disciplinar para a significação da linguagem disciplinar (física, química e biologia) e da linguagem interdisciplinar, via desenvolvimento da SE da referida área do conhecimento.
Os pós-graduandos, sujeitos do SA Participação pósgraduandos, comparecem a todas as reuniões do grupo e da escola. Eles dispõem das exposições teóricas para fundamentar suas dissertações e teses, usufruem das discussões que acontecem entre os seus integrantes, participam ativamente delas e, ao mesmo tempo, vão se familiarizando com o ambiente de pesquisadores e de professores pesquisadores de sua prática. Igualmente, participam ativamente das etapas de extensão quanto à produção curricular das SE e atuam na realização da pesquisa colaborativa entre a universidade e a escola.

O SA Participação licenciandos tem como sujeitos os licenciandos dos cursos de Química, Biologia e Física, que estão presentes nas reuniões do grupo e do NPE, desfrutam das informações e dos diálogos veiculados entre os componentes do grupo - e assim fundamentam teoricamente e metodologicamente seus TCC $-\mathrm{e}$ internalizam os saberes e conhecimentos de professor, os quais orientarão futuramente sua conduta pedagógica. Ou seja, participam ativamente na produção e elaboração do texto teórico e metodológico que constitui a SE.

O SA Apoio técnico-administrativo-pedagógico escolar é constituído pela equipe diretiva e coordenação pedagógica, que viabiliza a realização das reuniões do grupo com os NPE, no que se refere às instalações físicas para a sua realização, às convocações dos professores das diferentes áreas do conhecimento, bem como quanto aos materiais didáticos e pedagógicos de apoio para produção das aulas pelos professores.

O SA Coordenação do GEQPC, na pessoa do coordenador, sujeito desse SA, autoriza e coordena o fluxo das ações e operações entre o apoio técnico-administrativo-pedagógico escolar, a participação da escola parceira, os licenciandos, os pós-graduandos, os pesquisadores e os professores formadores, bem como atua também como professor formador interno. Como coordenador geral, introduz sempre novas problematizações acerca destas ações e de seus reflexos em termos de aprendizagens dos estudantes. Essas inserções acontecem por meio da própria produção das SE como um todo, da condução dos encontros presenciais, tanto aqueles mediados pelos coordenadores dos NPE quanto aqueles realizados no âmbito do GEQPC. Acontecem, também, por meio da introdução da prática de utilização dos instrumentos para a realização da pesquisa colaborativa, como a escrita em portfólio, e os relatos de experiências entre os integrantes do grupo. Enfim, trata-se de um sujeito mediador que atua diretamente nos diferentes SA.

Ao analisar-se o GEQPC sob a ótica dos oito SA, identifica-se prontamente o segundo princípio da TSA, o da multivocalidade, nas diferentes vozes (Bakhtin, 2003; 2003a) que os povoam, expressas nos interesses de todos os sujeitos componentes desses SA. Agora, ao se analisar os SA constituintes do GEQPC, do ponto de vista do SA Participação do professor da escola parceira, levanta-se a questão: quais vozes povoam este SA e o sujeito deste SA? Para respondê-la, lança-se mão do conceito bakhtiniano, circunscrito ao GP; porém, mesmo assim, é impossível caracterizar todas as vozes que povoam esse 
sujeito, pois eles são constituídos pela sua história, e o próprio SA é o conjunto da história dos seus artefatos mediacionais e das suas regras. Na tentativa de pontuar algumas vozes que povoam os sujeitos desse SA, pode-se citar a interlocução ocorrida nas reuniões do NPE e o material de apoio utilizado para a elaboração das SE. Além dessas vozes, digamos, internas ao GP, outras, externas, também povoam o SA Participação do professor da escola parceira: o livro didático, por sua tradição de uso em sala de aula, e todo o material de estudo do professor. A própria história da formação profissional dele é uma importante voz a povoar o sujeito na sua atividade nesse SA.

O terceiro princípio, historicidade, para o SA Participação do professor da escola parceira, circunscrito ao GEQPC, só pode ser entendido no período de constituição e de desenvolvimento deste SA em âmbito geral, ou seja, em contraste com a história das ideias e teorias de aprendizagem/formação de professores de Química, Física e Biologia, bem como com a relação desse professor e as teorias de currículo.

O quarto princípio é o do papel central que as contradições representam, como fontes de mudanças e de desenvolvimento. As contradições podem ser traduzidas em tensões, conflitos, problemas locais - lembrando, com Engeström et al. (1999), que contradições não são o mesmo que estes aspectos, mas algo mais abrangente, de maior amplitude. Localiza-se uma contradição bastante radical, nesta análise: o professor da escola tem de produzir as SE que, embora tenham um formato sugerido, permitem a ele exercer sua autonomia ao escolher uma temática orientada pelo seu contexto de atuação, um conceito a ser explorado em detrimento de outros, as relações interdisciplinares, e também ao desenvolver pedagogicamente a dinâmica das aulas que compõem as SE e ao propor tarefas avaliativas também à sua escolha. Essa lista de ações caracteriza uma contradição, ao considerar-se que estão a seu dispor prontos, nos livros didáticos, os conteúdos trabalhados pedagogicamente, em uma sequência tradicionalmente definida. Quer dizer, uma organização curricular tradicionalmente estabelecida. O que se soma a esta contradição é o fato de que o professor precisa seguir diretrizes curriculares governamentais que também estão expressas no material didático de uso corrente do professor. Esta contradição pode levar a conflitos: os professores podem resistir, não produzirem as SE ou mesmo copiarem os temas, conteúdos, estratégias metodológicas, tarefas avaliativas do material didático que têm à disposição no mercado editorial. Entretanto, também pode ser fator de alimentação do ciclo de transformações expansivas (Engeström et al., 1999) do SA Produção do professor da escola parceira, no sentido de contribuir para que o professor utilize em suas aulas algum elemento proveniente das SE por ele produzidas no intuito de complementá-las, ou mesmo modifica-las.

Segundo Engeström et al. (1999), o subtriângulo superior do triângulo dos SA (Figura 1) deve ser visto como a ponta de um iceberg, ou seja, com muitas ações individuais aninhadas representadas nele. Assim, passa-se a analisar ações individuais do sujeito professor da escola parceira no contexto da reunião do GP que serve como material empírico para a análise que segue.

\section{Episódio 1 - Perguntou-se aos Professores da Escola: Qual Foi a Primeira Dificuldade em Planejar a SE?}

Diálogo: Professor da Escola (PE1, PE2, PE3, PE4) e Pesquisador Visitante (PV)

[PE 1] Eu senti uma certa fragilidade ou insegurança: até quando eu posso avançar nesse conteúdo? Esse foi o primeiro ponto que incomoda, porque a gente está acostumado com aquela sequência que se aprende na escola, que a gente vê no livro didático, e que tu pega um assunto e aprofunda o máximo. E aí na SE tu fica com aquela dúvida incomodando. Até que ponto eu vou aprofundar? Porque eu tenho na situação de estudos vários elementos que vão aparecer e vários conteúdos que não necessariamente vão estar lá no primeiro ou no segundo, vai estar permeando o nosso currículo que vai atender $1^{\circ}, 2^{\circ}$ e $3^{\circ}$ ano, então essas coisas incomodam. Até porque não tenho experiência!!!

[PV] Posso fazer mais um comentário a respeito, eu acho que essa é uma questão crucial, aí tem que ver bem que uma situação de estudo está situada também no tempo de preferência, na divisão do tempo escolar. Por que nós temos que criar condições de factibilidade, não adianta nós produzir nas nuvens e na escola não vai funcionar por uma série de razões. As instituições têm regras, e a pesquisadora A tem um sistema de análise, que é um sistema de atividades que a gente vai poder testar bem como é que funciona, que é poder mostrar que existem muitas outras questões. Eu não sei, acho que aqui no RGS o período escolar é o trimestre, é isso? Aí o trimestre, ele envolve necessariamente o processo avaliativo, ele envolve um registro, envolve um tempo de execução, e uma atividade, então SE tem que ter essa preocupação também. Então a maior tentação, é o fato de você desvendar o real que tem uma característica incrível, ele é muito complexo. $\mathrm{O}$ real permite muitas coisas, muitas abordagens que aí você vai ter uma lista que não termina nunca. Isso a gente tem que logo entender que a $\mathbf{S E}$ tem a característica de delimitar o tempo.

Quando o PE1 questiona: “(...) até quando eu posso avançar nesse conteúdo, esse foi o primeiro ponto que incomoda, por que a gente está acostumada com aquela sequência que se aprende na escola, que a gente vê no livro didático", fica evidente que é preciso discutir o embasamento teórico que sustenta a SE, o qual requer uma mudança na lógica curricular 
que o próprio professor denuncia, qual seja, orientada por uma sequência, a mesma do livro didático. Uma mudança na forma estrutural do currículo e em suas metodologias exige uma mudança de concepção de currículo, por exemplo, no campo epistemológico. Segundo Maldaner (2007), os pressupostos epistemológicos de SE requerem compreensão do sentido de produção e validação da ciência.

Na sequência do diálogo, o PV argumenta sobre a importância de desvendar o real, via SE. Para isso, segundo ele, é preciso delimitar o tempo e estar atento para a escolha acerca do que deve ser trabalhado, considerando as condições do tempo escolar, qual seja, o trimestre.

Outro Professor da escola (PE2) (regente do Ensino Fundamental, com formação inicial em Pedagogia Alfabetização nos Anos Iniciais) também se pronuncia com relação ao tempo escolar para colocar em ação uma SE em sua sala de aula. Para esses professores que atuam nos anos iniciais do Ensino Fundamental, percebe-se menor ênfase na linearidade curricular em relação ao tempo escolar.

PE2: [...] na questão do currículo ... a gente tem uma prática... a gente encontra um pouco menos de dificuldade nessa questão porque se tem a questão temporal, você tem todo o ano com um grupo né, então você consegue perceber o aluno, você consegue conhecer o aluno, sabe quem vai ter dificuldade no que e isso ajuda bastante né. Assim ó, trabalhando com os pequeninhos foi minha primeira experiência, é bom .... a gente contribui um pouco mais e é muito rico como a colega falou essa troca porque no currículo apesar de se conhecer o aluno essa troca também é deficiente. A gente se encontra pouco pra partilhar esse saber tanto que elas preparam a mesma coisa...e nós não havíamos trocado essa percepção... uma construção em cima da percepção de todos.

O professor PE2 esclarece que, por ficar o ano letivo inteiro com os mesmos alunos, tem a vantagem de conhecê-los, perceber as suas dificuldades e progressos, e assim consegue administrar com mais facilidade o tempo pedagógico em relação ao que propõe a SE. De modo que o entendimento de que a escolha do que vai ser trabalhado depende do professor é uma característica importante da SE, e precisa de um tempo para o seu encaminhamento, conforme pontuou o Pesquisador Visitante.

\section{Episódio 2 - Conceitos da TA e TSA no Planejamento e Execução da SE}

[PE3] Em uma das reuniões na segunda feira, a gente falava sobre isso, dentro da química mesmo, uma atividade experimental, ligar o led direto no soluto, o sal. O livro disse que não vai conduzir, mas se pegarmos um dia muito úmido aqui [refere-se ao lugar] o led acende. Então são situações reais, é um processo investigativo e aí a gente tem que estar preparado para essas eventualidades. É importante fazer o experimento antes, para se preparar para futuras eventualidades. Que o livro que é idealizado em modelos e a gente está trabalhando o experimental na situação real. Às vezes pode fugir do modelo. [PV] Então aí que está, para cada situação que iremos planejar, ele vai ter que olhar, bom! Eu tenho essa SE, ela se presta muito bem para determinada matéria e tal, e eu teria esse conjunto de conceitos preliminarmente planejados, preliminar. E aí como é que se organizam as aulas? essas aulas na linguagem que a pesquisadora $\mathrm{A}$ trouxe, diz que se a gente conseguir adaptar a uma SE ela envolve uma ação, e um planejamento de uma aula passa a ser uma ação. E se essa ação vai se desencadear na aula mesmo, a operação.

A "pesquisadora A" citada pelo Pesquisador Visitante é o sujeito Professor Formador (PF) externo ao GEQPC.

Ficou claro para o professor da escola que trabalhar com situações reais levam as aulas para um nível de maior complexidade. Dessa forma, desenvolver as aulas que compõem a SE requer um planejamento. A atividade de planejar compreende, segundo a TA, um motivo, uma ação ou ações e operação (Leontiev, 1988). Segundo Leffa (2005), um dos fundamentos da TA é a capacidade do sujeito relacionar conscientemente os três níveis. Assim, a atividade de planejar consta das relações entre as ações, a exemplo de delimitar os conceitos a serem abordados, em certas condições de operação, ou seja, em um tempo escolar trimestral. Quando o motivo, a produção do currículo por SE, ou seja, a necessidade do sujeito PE, coincidir com o objeto da atividade, tem-se reconhecidamente uma Atividade.

O Pesquisador Visitante contribui na afirmativa dessa categoria quando argumenta:

[PV] Então no planejamento e na produção da SE, a gente vai ter que planejar as ações, as diversas aulas, que vamos dar. Mas o importante é que nesses processos a gente terá que fazer alguns cortes [tomada de decisão]. Esta aqui, por exemplo, pode ficar uma questão aberta. Lá no livro está escrito, com tal situação não ia conduzir [eletricidade]. Bom, isso poderá ser explorado como projeto específico: Aí então o grupo de alunos, diria, gostaríamos de avançar nisso e passar à produção dos alunos. E aí na SE sempre deverá ter esse meio que são as execuções dos planejamentos das ações: suas operações, das mais diversas maneiras, como a pesquisadora A já citou e nós vamos tentar achar explicitações disso, nós só temos esquemas, aí o aluno produzindo [...].

Nesse trecho é notável o conhecimento do PV, ao contextualizar a atividade de produção e execução da SE tendo como 
fundamento teórico a TA, a partir da identificação dos três níveis: atividade, ação e operação (Leontiev, 1988). A 'atividade' está relacionada às necessidades humanas e é orientada para o objeto. Neste caso, a atividade é produzir currículo por SE. A ação constitui as metas a serem alcançadas, ou seja, definir uma SE a ser desenvolvida, planejar as aulas que irão compor a SE, delimitar os conceitos científicos a serem significados, dentre outras ações. As operações são as condições de realização da ação. Por exemplo: definir uma SE a ser desenvolvida fazendo uma consulta à comunidade do entorno escolar por meio de entrevistas. Ou, planejar as aulas que irão compor a SE utilizando material pesquisado na internet. Ou ainda, utilizando livros paradidáticos, etc. Assim, produzir SE significa produzir algo próprio, de sua autoria, que caracteriza uma marca significada desse sujeito professor em atividade de produção curricular.

\section{Episódio 3 - A Motivação para o Surgimento de uma Nova Atividade}

[PE4] Assim ó, eu me vi no primeiro dia com o professor visitante, vários aspectos eu cheguei me enxergar nele, assim né, nas dúvidas, questões, pontos de interrogações e que me levaram a fazer vários questionamentos sobre a minha prática e como eu estava trabalhando. Hoje, vendo a senhora falar, eu achava que quando eu comecei a fazer as minhas coisas, eu trouxe até outro dia, e a [refere-se à coordenadora do GEQPC], olhou a Prof ${ }^{a}$ [refere-se a outro sujeito professor de Escola] que trabalha comigo, até assim ó eu me achei um pouquinho, eu me fazia os questionamentos: será que estou sendo aquela professora do ensino médio que o meu aluno precisa ou será que não estou sendo muito mãezona? Aquela professora do ensino fundamental que de repente pega lá aqueles conteúdos básicos de $5^{\circ}$ e $6^{\circ}$ ano, eu queria produzir a situação de estudo, então eu pensei em mostrar porque de repente eu estivesse fazendo correto. Olhando o teu material aqui eu me enxerguei realmente, me vi exatamente. Coisas básicas e vendo que resgata conceitos básicos que eles tiveram né para introduzir um novo conceito e me vi assim, estou numa caminhada correta, eu busco coisas de repente eles tenham ouvido falar para introduzir um novo conceito. E pegando outra fala que tu falaste do mapa conceitual. Eu estou assim ó, depois da greve, quando entrou a greve eu estava entrando em soluções que a situação de estudo é exatamente água com eles e aí eu pedi para eles trazerem rótulos, eu comentei com [refere-se a outros professores]. E coordenadora do GEQPC disse assim, ah é importantíssimo, mas eu não comentei nada com ela o que eu ia fazer e a partir dos rótulos eu ia montar exatamente um mapa conceitual sobre soluções [...]. A situação de estudo me proporcionou também trabalhar com outros professores. Eu trabalhei com a Prof ${ }^{a}$ de Artes, no $1^{\circ}$ ano e aí nós fizemos um trabalho porque a gente construiu um jornal-mural, [...] depois a [refere-se a professora da Escola] me chamou pra trabalhar tinta com eles que a gente não sabia como botar em prática, daí ela queria trabalhar tintas e aí trabalha toda a questão de química nessa situação e daí a gente não conseguia botar em prática então a situação de estudo. Hoje eu já estou vendo ela como um novo horizonte já com a coisa mais aberta, já me desprendendo daquela coisa assim de pegar o livro didático e preparar isso e isso. Hoje eu já consigo enxergar um panorama diferente!

Semelhante ao Episódio 2, esse outro professor da escola também não tinha conhecimento sobre os pressupostos e princípios imbricados na SE, mas não teve receio de trabalhar os conceitos, os quais ele compreendia serem necessários para o desenvolvimento da SE, a exemplo da água. Percebe-se em PE4 entusiasmo pela temática água, reconhecendo que se sentia confortável movendo-se na abordagem conceitual. Segundo seu relato, a professora promoveu ações para que os alunos se apropriassem dos conceitos como artefatos mediacionais para a compreensão da temática água, alinhando-se a este importante propósito da SE. Segundo Leontiev (1978),

A primeira condição de toda a atividade é uma necessidade. Todavia, em si, a necessidade não pode determinar a orientação correta de uma atividade, pois é apenas no objeto da atividade que ela encontra a sua determinação: deve, por assim dizer, encontrar-se nele. Uma vez que a necessidade encontra a sua determinação no objeto (se "objetiva" nele), $o$ dito objeto torna-se motivo da atividade, aquilo que o estimula (Leontiev, 1978, p. 115).

Em outras palavras, a Atividade, segundo o autor, tem como característica o motivo pelo qual o sujeito se dispõe a agir diante de uma necessidade. Assim, PE4 tinha uma necessidade, qual seja, produzir uma SE, que se objetivou na SE (o objeto da atividade de PE4 é a SE), a qual também se tornou o motivo da atividade de PE4.

[PV] Em primeiro lugar no ensino médio a característica é disciplinar, existe a disciplina, mas existe uma ideia bastante forte nos documentos que jogam que as disciplinas precisam ser percebidas dentro de uma área de conhecimentos e que isso também vai repetir-se no $5^{\circ}$ ao $9^{\circ}$ ano e obviamente nos outros também. No ensino médio a característica por área é importante e aí também é importante a interdisciplinaridade, ou seja, um sistema de conceitos que não é nada mais, nada menos que um mapa conceitual. Quando fala mapa conceitual ele fixa um signo 
num sistema mais aberto. Bom, existe na minha opinião uma ideia e eu gostei muito do esquema que a [coordenadora do GEQPC] apresentou ontem que vocês viram que existe uma situação de estudo e aí vem uma pergunta central e de área. Qual é o objetivo que existe entre as áreas, que seria então aquilo que engloba a escola como um todo? Então essa é uma pergunta importante! Mas também existem as perguntas específicas: Que as ciências da Natureza propõem como um todo para esse período escolar, digamos o trimestre. Bom, então como isso é encaminhado na prática? Para isso precisa do planejamento coletivo. E vocês têm na escola a ideia do professor por áreas se reunir ter o dia de reunião e isso é importante!!!

PV pontua sobre as condições de operação do planejamento coletivo a fim de direcionar as tarefas, bem como as ações que esta atividade abrange, no sentido de intencionalidade na área e nos componentes específicos, como responder a uma problemática por meio dos conteúdos. Os conteúdos, no caso, são artefatos mediacionais e definem o grau de compreensão dos conceitos, os quais pertencem a um sistema conceitual em maior ou menor generalidade. São compreensões que precisam ser apreendidas, significadas nessas interações de formação, na interface universidade e escola. Nessa direção, a compreensão do referencial teórico que fundamenta a SE, bem como os fundamentos que pautam a pesquisa sobre essa atividade, constituem níveis de consciência que podem evoluir, e espera-se de fato que evoluam, durante o processo de produção da SE. Nota-se que a fala de PE4 mostra que suas ações estão se encaminhando para cumprir os objetivos estipulados teoricamente pela SE.

Assim, as ações dos sujeitos professores PE1, PE2, PE3 e PE4 fazem com que o objeto da sua Atividade (a SE) apareça na relação com o motivo da atividade (produção da SE), pois, de acordo com Leontiev (1978, p. 317): "Não levando o objeto da ação, por si próprio, a agir, é necessário que a ação surja e se realize, que o seu objeto apareça na relação com o motivo da atividade em que entra essa ação". Para isso, é imprescindível a realização da ação pelo sujeito que, desse modo, é transformada em atividade, ou seja, em processo constitutivo/formativo.

Então, de acordo com os pressupostos teóricos considerados, entende-se que colocar o professor em atividade é indispensável para o bom êxito do processo formativo. No caso, trata-se da atividade de produção de SE, a qual é, no caso, o dispositivo formativo subjacente à atividade de desenvolvimento curricular, em que o professor assume protagonismo. Os professores da escola iniciaram o processo de produção e desenvolvimento das situações de estudo, explicitando, assim, critérios na escolha do tema, dos conteúdos e dos conceitos, e seu alcance em termos de aprendizagem dos estudantes, dentre outras ações.

\section{Considerações Finais}

A realização da atividade de produção de SE e seu acompanhamento pela pesquisa indicam que, na relação GEQPC e escola parceira, existem muitos sistemas de atividades em curso, dos quais dois foram identificados e analisados neste trabalho. Os SA identificados comprovam a existência dos processos formativos. Identificaram-se processos formativos na realização da atividade de produção da SE (motivo, ação e operação) que estão constituindo e mediando as interações entre o grupo de pesquisa GEQPC e a escola de educação básica, e sinais promissores de que tal atividade evoluirá para a prática da pesquisa colaborativa entre os sujeitos dos SA pertinentes. Pode-se mencionar ainda o processo de pesquisa que o professor da escola vivencia ao produzir a SE, quando o acompanha, em ações como descrever, discutir, analisar, interpretar à luz da teoria.

Com isso, um processo de formação está presente, porém, de forma subjacente. Ao serem explicitadas suas intencionalidades, passa a contribuir para o desenvolvimento de habilidades, justamente porque os participantes dos processos interativos em "tríades" desenvolvem ações com aportes teóricos e metodológicos que fundamentam a produção da SE e a consequente reorganização curricular.

Nesta fase inicial de construção da SE, é reconhecida a necessidade dos grupos GEQPC e núcleos de pesquisa na escola trabalharem intensamente em conjunto, no sentido de apoiar teórica e metodologicamente a produção curricular.

A fundamentação teórica de abordagem histórico-cultural, que permeia este movimento formativo para todos os sujeitos no SA Pesquisa no GEQPC, mostrou-se relevante e está em processo de apropriação por todos os sujeitos. Com isso as atividades, produção de SE e desenvolvimento de currículo por SE, tornam-se, também, objeto de pesquisa a ser realizada pelos outros integrantes do GEQPC. Tanto a significação conceitual que fundamenta a SE (Vigotski, 2001), quanto a sua análise em fase de produção e desenvolvimento pela TA e TSA, constituem objetos de estudo e pesquisa.

Percebeu-se que, com o desenvolvimento dos trabalhos no GEQPC, diversos SA irão interrelacionar-se e, dessa forma, novas redes poderão ser estabelecidas, proporcionando outras interações constitutivas.

\section{Notas}

${ }^{1}$ Disponível em https://www.helsinki.fi/en/researchgroups/ center-for-research-on-activity-development-and-learning, acessada em Janeiro 2019.

${ }^{2}$ Disponível em https://www.iscar.org, acessada em Janeiro 2019.

${ }^{3}$ Disponível em https://iscarbrasil.wordpress.com/, acessada em Janeiro 2019. 


\section{Referências}

ARAÚJO, M. C. P.; AUTh M. A. e MALDANER. O. A. Autoria compartilhada na elaboração de um currículo inovador em ciências no ensino médio. Contexto \& Educação, n. 77, p. 214-262, 2013.

AUTH, M. A.; MALDANER, O. A.; WUNDER, D. A.; FIUZA, G. S. e PRADO, M. C. Situações de estudo na área do ensino médio: rompendo fronteiras disciplinares. In: MORAES, R. e MANCUSO, R. (Eds.). Produção de currículos e formação de professores. Ijuí: Ed. Unijuí, 2004.

BAKHTIN, M. Estética da criação verbal. São Paulo: Martins Fontes, 2003.

. Marxismo e filosofia da linguagem: problemas fundamentais do método sociológico na ciência da linguagem. Trad. M. Lahud e Y. F. Vieira com a colaboração de L. T. Wisnik e C. H. D. C. Cruz. $9^{a}$ ed. São Paulo: Hucitec/Annablume, 2003a.

BARDIN. L. Análise de conteúdo. Lisboa: Edições 70, 1977.

BRASIL. Ministério da Educação. Conselho Nacional de Educação. Resolução n. 2 de $1^{o}$ de julho de 2015. Disponível em http://portal. mec.gov.br/docman/agosto-2017-pdf/70431-res-cne-cp-00203072015-pdf/file, acessado em Janeiro 2019.

DANIELS, H. Vygotsky e a pedagogia. São Paulo: Edições Loyola, 2003. ENGESTRÖM, Y.; MIETTINEN, R. e PUNAMAKI, R. (Orgs.). Perspectives on activity theory. Cambridge: Cambridge University Press, 1999.

GEHLEN, S. T.; ALBRECHT, M. R. A. e AUTH, M. A. Implicações curriculares no ensino fundamental: área de ciências naturais. In: Atas do IV Encontro Ibero-Americano de Coletivos Escolares e Redes de Professores que Fazem Investigação na sua Escola. Lajeado, RS, 2005.

LEFFA, V. J. Aprendizagem mediada por computador à luz da teoria da atividade. Calidoscópio, v. 3, n. 1, p. 21-30, 2005.

LEONTIEV, A. N. O homem e a cultura. In: LEONTIEV, A. N. $O$ desenvolvimento do psiquismo. Lisboa: Livros Horizonte, 1978.

Uma contribuição à teoria do desenvolvimento da psique infantil. In: VIGOTSKI, L. S.; LURIA, A. R. e LEONTIEV, A. N. Linguagem, desenvolvimento e aprendizagem. São Paulo: Ícone, 1988.

LIMA, G. S. e GIORDAN, M. O movimento docente para o uso da divulgação científica em sala de aula: um modelo a partir da teoria da atividade. Revista Brasileira de Pesquisa em Educação em Ciências, n. 18, p. 493-520, 2018.

MALDANER. O. A. Situações de estudo no ensino médio: nova compreensão de educação básica. In: NARDI, R. (Org.). A pesquisa em ensino de ciências no Brasil: alguns recortes. São Paulo: Escrituras, 2007. e ZANON, L. B. Situação de estudo: uma organização curricular do ensino que extrapola a formação disciplinar em Ciências. Espaços da Escola, n. 41, p. 45-60, 2001.

MASSI, L. e GIORDAN, M. A formação do pesquisador e do professor no ensino de ciências como sistemas de atividade. Enseñanza de las Ciencias, n. extra, p. 2769-2774, 2017.

NERY. B. K. O ciclo de desenvolvimento do professor e o sistema de atividades aprendizagem on-line em um curso de especialização em ensino de ciências. Tese (Doutorado em Educação). Universidade de São Paulo, São Paulo, 2014.

e GIORDAN, M. Fundamentos da teoria dos sistemas de atividades para organizar e interpretar programas de formação continuada de professores em ambientes virtuais de aprendizagem. In: CARVAlHO, A. M. P. (Org.). Formação de professores: múltiplos enfoques. São Paulo: Sarandi, 2013.

RITTER. J. Recontextualização de políticas públicas em práticas educacionais: novos sentidos para a formação de competências básicas. Curitiba: Appris, 2017.

SCHNETZLER, R. P. A pesquisa em ensino de química no Brasil: conquistas e perspectivas. Química Nova, v. 25, p. 14-24, 2002.

VASCONCELOS, A. R. A.; RITTER, J.; UMPIERRE, A. B. e SOUSA, T. B. G. Processos de mediação de currículo na interface universidade e escola. Enseñanza de las Ciencias, n. extra, p. 2413-2417, 2017.

VIEIRA, L. B. G.; FERNANDES, G. W. R.; MALDANER, O. A. e MASSENA, E. P. Situação de estudo: o que vem sendo publicado em eventos e periódicos na área de ensino de ciências? Ensaio Pesquisa em Educação em Ciências, v. 20, e2914, 2018.

VIGOTSKI, L. S. A construção do pensamento e da linguagem. Trad. P. Bezerra. São Paulo: Martins Fontes, 2001.

A formação social da mente: o desenvolvimento dos processos psicológicos superiores. Trad. J. Cipolla Neto; L. S. M. Barreto e S. C. Afeche. $7^{\mathrm{a}}$ ed. São Paulo: Martins Fontes, 2007.

Pensamento e linguagem. Trad. J. L. Camargo. $3^{\mathrm{a}}$ ed. São Paulo: Martins Fontes, 2005.

ZANON, L. B. Interações de licenciandos, formadores e professores na elaboração conceitual de prática docente: módulos triádicos na licenciatura em química. Tese (Doutorado em Educação). Universidade Metodista de Piracicaba, Piracicaba, 2003.

\section{Para Saber Mais}

ENGESTRÖM, Y. Studies in expansive learning: learning what is not yet there. New York: Cambridge University Press, 2016.

MOURA, M. O. A atividade pedagógica na teoria histórico-cultural. Brasília: Liber Livro, 2010. 